\title{
Anaerobic Digestion Characteristics and Key Microorganisms Associated With Low-Temperature Rapeseed Cake and Sheep Manure Fermentation
}

\section{Li Liu}

Academy of Agriculture and Forestry Sciences, Qinghai University

\section{Rongbo Xiong}

Academy of Agriculture and Forestry Sciences, Qinghai University

Yi Li

Academy of Agriculture and Forestry Sciences, Qinghai University

Laisheng Chen

Academy of Agriculture and Forestry Sciences, Qinghai University

Rui Han ( $\nabla$ hanrui11473@163.com )

Academy of Agriculture and Forestry Sciences, Qinghai University https://orcid.org/0000-0002-7599-384X

\section{Research Article}

Keywords: rapeseed cake, sheep manure, low temperature, anaerobic digestion, microbial analysis

Posted Date: November 15th, 2021

DOI: https://doi.org/10.21203/rs.3.rs-1055064/v1

License: @ (i) This work is licensed under a Creative Commons Attribution 4.0 International License. Read Full License

Version of Record: A version of this preprint was published at Archives of Microbiology on February 22nd, 2022. See the published version at https://doi.org/10.1007/s00203-022-02796-y. 


\section{Abstract}

Qinghai rural household biogas digesters were used to evaluate fermentation characteristics, including gas production and key microbial community changes, associated with low-temperature $\left(15.2-17.8^{\circ} \mathrm{C}\right)$ mixed rapeseed cake and sheep manure anaerobic fermentations across 40 days using seven different ratios of material. Different raw material ratios resulted in significantly different effects on biogas yields and microbial community compositions. When the ratio of sheep manure to rapeseed cake was 1:2, the highest level of cumulative gas production was observed $\left(122.92 \mathrm{~m}^{3} \cdot \mathrm{t}^{-1}\right)$. Firmicutes, Proteobacteria, Bacteroidetes, and Actinobacteria were the dominant bacterial phyla among the 29 digester samples (total relative abundances $>79.23 \%)$, followed by Synergistetes (4.09\%-10.7\%). Lactobacillus was the most abundant genus in the biogas digesters with high rapeseed cake contents (average relative abundances: $14.68 \%$ ), while Peptoniphilus exhibited higher abundances (12.69\%) in the mixed fermentation digester treatments. In addition, unclassified Synergistaceae abundances (6.64\%) were positively associated with biogas production variation among treatments. Bacteroides (5.74\%) and Pseudomonas (5.24\%) both accounted for larger proportions of communities in the digesters that used more sheep manure. Methanomicrobiales (66.55\%) was the most dominant archaeal group among digesters, with Methanogenium (41.82\%) and Methanoculleus (16.55\%) representing the main gas-producing archaeal genera; they were more abundant in biogas digesters with higher sheep manure contents and higher rapeseed cake contents, respectively. Regardless of the raw material ratios, Methanoculleus exhibited the highest abundances on the 4th day of fermentation. VFAs and pH were the main factors associated with differences in microbial communities among the 29 samples. Specifically, VFA concentrations were positively correlated with Lactobacillus and Methanoculleus abundances, while $\mathrm{pH}$ was positively correlated with Bacteroides, Pseudomonas, Methanobrevibacter, and Methanobacterium abundances.

\section{Introduction}

Rapeseed cake is a by-product that is obtained by pressing rapeseed to make oils. The cakes have abundant protein, amino acid, and other nutrient components and are agricultural solid wastes that can be reused as important resources. The annual global output of rapeseed cake is about 40 million tons (Stein et al. 2016). Concomitantly, the annual output of livestock and poultry manure in China is estimated to be 3.26 billion tons (Wang et al. 2019). The rampant accumulation and inefficient treatment of agricultural wastes like rapeseed cake and sheep manure have caused serious environmental pollution problems in China.

Anaerobic fermentation technology is a clean and efficient way to utilize agricultural waste resources. These techniques can effectively reduce the consumption of non-renewable energy and biomass resources in China, while also promoting the sound development of ecological agriculture (Wang et al. 2020; Zhai et al. 2020). Qinghai Province is located in the northeastern region of the Qinghai-Tibet Plateau and is situated at an average altitude of over 4,000 $\mathrm{m}$ and exhibits an average annual temperature of only $7.2^{\circ} \mathrm{C}$. Low temperatures affect the development of the biogas industry in Qinghai, resulting in biogas utilization efficiency being far lower in this area compared to low altitude areas. Thus, numerous agricultural biogas digesters have been abandoned in the area and these wasted resources represent a serious problem (Tian et al. 2019; Yang et al. 2020; Han et al. 2020). However, the selection of easily degradable raw materials (Li et al. 2020), the fermentation of mixed substrate components (Shi et al. 2021) and fermentations with high solid contents (Elmitwalli et al. 2004) can adequately reduce environmental condition requirements for fermentation. Further, they can partially compensate for the low gas production rates caused by low temperatures. Consequently, research into high solid content and low temperature mixed anaerobic fermentation of rapeseed cake and sheep manure carries important significance for the development of biogas application technologies under the low temperature conditions present in Qinghai Province.

Anaerobic digestion is a complex microbiological process that is accomplished by a variety of anaerobic microorganisms, rendering it difficult to comprehensively evaluate these ecosystems using traditional culture-based microbiological analyses. However, 16S rRNA gene high-throughput sequencing can accurately assess the structural characteristics of various microbial communities using genetic techniques. High-throughput sequencing techniques have been widely used to study 
complex microbial communities. Arelli et al. (2021), Bae et al. (2020), and Tao et al. (2021) have applied this technology to investigate the microbial community structural characteristics during co-digestion of meal waste and waste sludge. Acetyl compound catalysis is the primary metabolic pathway associated with digestion, and increased food waste levels leads to higher microbial abundances in digestors. Jang et al. (2014) used high-throughput sequencing technology to reveal the impact of different organic loads on the microbial community in the anaerobic digestion of wastewater.Likewise, highthroughput sequencing was used by Ndubuisi-Nnaji et al. (2020) to investigate changes in the microbial community structures during the co-digestion of corn stover, rice straw, and sheep manure, observing that the co-digestion microbial communities exhibited higher abundances. Yang et al. (2019) also used high-throughput sequencing and observed that the most favorable metabolic pathway during pig manure fermentation was the production of hydrogen in some communities, followed by the reduction of carbon dioxide to produce methane.

Previous studies have referred to anaerobic fermentation below $20^{\circ} \mathrm{C}$ as low-temperature fermentation, and fermentation conditions of rural household biogas digesters in Qinghai Province belong to this category (Han et al. 2020; Tiwari et al. 2021). In this study, we investigated rural household biogas digesters that were used as fermentation devices to conduct lowtemperature $\left(15.2-17.8^{\circ} \mathrm{C}\right)$ pilot experiments to specifically evaluate biogas production by mixed anaerobic fermentation of rapeseed cake and sheep manure using seven different ratios of high solid content waste. In addition, the microbial community structural dynamics were analyzed across the fermentation process. The results provide insights into the associations among microbial communities and environmental factors in digesters of this area, revealing relationships between the structures and functions of microbial communities, thus providing a theoretical basis for better resource utilization of agricultural wastes like rapeseed cake and sheep manure. These results also provide a technological framework that can be used to promote the application of agricultural wastes during low-temperature anaerobic fermentation treatment technology in Qinghai Province and other cold regions of northern China.

\section{Materials And Methods}

\section{Experimental materials}

Rapeseed cake was collected from the Farmers' Market at Duoba Town in Huangzhong County of Qinghai Province and ground to a particle size of less than $30 \mathrm{~mm}$. Sheep manure was retrieved from Guinan County in Qinghai Province. The inoculum was taken from a rural household biogas digester fermented with sheep manure from Qinghai Province.

Fermentation material and inoculum characteristics are shown in Table 1.

Table 1

Physical and chemical properties of raw materials and inocula used for digesters in this study

\begin{tabular}{|lcccccccc|}
\hline $\begin{array}{l}\text { Test } \\
\text { sample }\end{array}$ & pH & TS (\%) & VS (\%) & C (\%) & Lignin (\%) & $\begin{array}{l}\text { Cellulose } \\
(\%)\end{array}$ & $\begin{array}{l}\text { Hemicellulose } \\
(\%)\end{array}$ & $\begin{array}{l}\text { Crude } \\
\text { protein } \\
(\%)\end{array}$ \\
\hline $\begin{array}{l}\text { Rapeseed } \\
\text { cake }\end{array}$ & $6.34 \pm 0.1$ & $92.35 \pm 0.3$ & $84.88 \pm 0.2$ & $45.3 \pm 0.5$ & $10.91 \pm 0.6$ & $3.37 \pm 0.1$ & $3.35 \pm 0.1$ & $30.5 \pm 0.6$ \\
$\begin{array}{l}\text { Sheep } \\
\text { manure }\end{array}$ & $7.87 \pm 0.0$ & $38.48 \pm 0.0$ & $30.07 \pm 0.1$ & $38.24 \pm 0.4$ & $33.73 \pm 0.4$ & $14.50 \pm 0.3$ & $9.81 \pm 0.5$ & $11.63 \pm 0.2$ \\
\hline $\begin{array}{l}\text { Inoculum } \\
\text { Note: ND means not determined }\end{array}$ & & & & & & ND & ND & ND \\
\hline
\end{tabular}

\section{Experimental digesters}

Rural household biogas digesters from Qinghai Province $\left(36^{\circ} 3^{\prime} 11^{\prime \prime} \mathrm{N}, 101^{\circ} 19^{\prime} 36^{\prime \prime} \mathrm{E}\right)$ were used as fermentation devices. All biogas digesters exhibited identical structures and comprised underground hydraulic spherical biogas digesters with a 
volume of $8 \mathrm{~m}^{3}$ and a charging volume of about $5 \mathrm{~m}^{3}$. Each biogas digester was connected to a biogas flow meter to record biogas production. A Rc-4 temperature recorder was connected to each biogas digester that automatically recorded fermentation temperatures every $2 \mathrm{~h}$.

\section{Experimental design}

Rapeseed cake and sheep manure were mixed using seven ratios (Table 2) including 1) pure sheep manure (S), 2) pure rapeseed cake $(R), 3)$ sheep manure and rapeseed cake mixed at a 1:1 ratio $\left(S_{1} R_{1}\right)$, 4) sheep manure and rapeseed cake mixed in a 2:1 ratio $\left.\left(S_{2} R_{1}\right), 5\right)$ sheep manure and rapeseed cake mixed at a 3:1 ratio $\left.\left(S_{3} R_{1}\right), 6\right)$ sheep manure and rapeseed cake mixed at a 4:1 ratio $\left(S_{4} R_{1}\right)$, and 7) sheep manure and rapeseed cake mixed at a 1:2 ratio $\left(S_{1} R_{2}\right)$. The total dry matter used in each group was equivalent, and the solid content was adjusted to $16 \%$, with two parallel experiments being used for each group. In each treatment, different raw materials were evenly stirred with a specified level of biogas slurry (with moisture content adjusted to $70 \%$ ), covered with plastic film for heap retting over five days, and stirred every day during heap retting. Digester materials were mixed with $1,500 \mathrm{~kg}$ of inoculum ( $30 \%$ inoculum) and then biogas slurry was supplemented to a volume of $5 \mathrm{~m}^{3}$. The biogas flow rate was recorded regularly every day starting on the second day after filling the biogas digesters. Fermentation liquid was collected from the biogas digester waters for sampling every three days with a selfconstructed sampler to determine the physical and chemical properties of the fluids in addition to digester microbial community structures.

Preliminary data indicated that Qinghai rural household biogas digesters exhibited the highest fermentation temperatures from early to mid-August into mid-September, suggesting that these were the most suitable times for anaerobic fermentation ${ }^{[7]}$. The experiments of this study were consequently initiated on August 3, 2020 and ended on September 11, 2020 , comprising a total of 40 days. The fermentation temperature range for each group was $15.2-17.8^{\circ} \mathrm{C}$ and the temperature difference before and after fermentation was $0.9-1.3^{\circ} \mathrm{C}$ following self-stabilization, indicating an essentially constant fermentation temperature within the biogas digesters.

Table 2

Amount of raw materials added to digesters used in this study

\begin{tabular}{|lll|}
\hline Treatment group & Rapeseed cake $(\mathbf{k g})$ & Sheep manure $(\mathrm{kg})$ \\
\hline $\mathrm{S}$ & 0.00 & $1,986.62$ \\
\hline $\mathrm{R}$ & 827.77 & 0.00 \\
\hline $\mathrm{S}_{1} \mathrm{R}_{1}$ & 413.89 & 993.31 \\
\hline $\mathrm{S}_{2} \mathrm{R}_{1}$ & 275.92 & $1,324.41$ \\
\hline $\mathrm{S}_{3} \mathrm{R}_{1}$ & 206.94 & $1,489.96$ \\
\hline $\mathrm{S}_{4} \mathrm{R}_{1}$ & 165.55 & $1,589.29$ \\
\hline $\mathrm{S}_{1} \mathrm{R}_{2}$ & 551.85 & 662.21 \\
\hline Note: Weight was calculated based on dry matter in units of $\mathrm{kg}$. \\
\hline
\end{tabular}

\section{Fermentation physicochemical properties}

Total solids (TS) and volatile solids (VS) were determined using the drying method, wherein the total solids were dried in an oven at $105^{\circ} \mathrm{C}$ for $24 \mathrm{~h}$ and the volatile solids were burned in a muffle furnace at $550^{\circ} \mathrm{C}$ for $3 \mathrm{~h}$. Ammonia nitrogen content was determined as previously described (Hu et al. 2017), along with volatile fatty acid (VFA) concentration measurements 
(Shi et al. 2021). pH was measured with a pH meter (pHS-2F), and alkalinity content was measured with a potentiometric titrator (ZDJ-4A). Total carbon content was determined as previously described (Kainthola et al. 2020), as were lignin, cellulose, and hemicellulose content measurements ( $\mathrm{Li}$ et al. 2020), in addition to crude protein content measurements (Bae et al. 2020).

\section{Biogas production modeling}

Dynamic models can express experimental results with more precise mathematical formulas, enabling a more in-depth understanding of complex anaerobic digestion processes and providing a corresponding theoretical framework (Zhang et al. 2016). The Gompertz equation (Eq. 1) was used to describe biogas production potential by fitting the model to cumulative biogas production from anaerobic fermentation of rapeseed cake and sheep manure:

$P=P_{m} \cdot \exp \left\{-\exp \left[\frac{R_{m} \cdot e}{P_{m}}(\lambda-t)+1\right]\right\}$

In the equation, $\mathrm{P}$ is the cumulative methane production of VS corresponding to time $\mathrm{T}$ (in $\mathrm{m}^{3} \cdot \mathrm{t}^{-1}$ ), $\mathrm{Pm}$ is the final cumulative VS biogas production (in $\mathrm{m}^{3} \cdot \mathrm{t}^{-1}$ ), Rm is the maximum VS gas production rate (in $\mathrm{m}^{3} \cdot(\mathrm{t} \cdot \mathrm{d})^{-1}$ ), $\lambda$ is the gas production retention time (in d), $T$ is the fermentation time (in d), and $E$ is the constant $\exp (1)=2.7183$. The model fitting results were used to calculate the maximum VS gas production rate, $\mathrm{Rm}$, and the gas production retention time, $\lambda$.

\section{Sample collection}

Seven biogas digesters with different raw material ratios were used in this study and biogas slurry samples were taken on the 4th, 16th, 28th, and 40th days of fermentation. Biogas slurry samples from the upper, middle, and lower layers of the biogas digesters were collected and mixed during sampling. Samples in each fermentation group were identified by the group and the fermentation time (e.g., for the S group: S_4, S_16, S_28, and S_40). Digesters inoculated with sheep manure as fermentation substrate were used as controls and identified as the CK samples.

\section{Extractionof digester sludge genomic DNA}

Sludge sample genomic DNA was extracted using a Qiagen QIAamp Fast DNA Stool Mini Kit and quality was evaluated with $1 \%$ agarose gel electrophoresis, wherein a clear primary DNA band without signs of degradation was required for further analysis. DNA concentrations and purities were then evaluated using a NanoDrop 2000 ultra-micro spectrophotometer prior to sequencing, with requirements of sample concentrations $>10 \mathrm{ng} / \mu \mathrm{L}$, total sample volume $>500 \mathrm{ng}$, and $\mathrm{A}_{260 / 280}$ values ranging from 1.8 to 2.0 .

\section{High-throughput sequencing}

High-throughput sequencing of bacterial and archaeal 16S rRNA genes was conducted at Hangzhou Lianchuan Biotechnology Co., Ltd. Bacterial-specific PCR primers were used to amplify $16 \mathrm{~S}$ rRNA gene fragments including 341F (5'CCTACGGGNGGCWGCAG-3') and 805R (5'-GACTACHVGGGTATCTAATCC-3'), while the archaeal-specific primers, 'F' (5'TGYCAGCCGCCGCGGTAA-3') and ' $R$ ' (5'-YCCGGCGTTGAVTCCAATT-3'), were used in separate reactions. PCR products were confirmed by $2 \%$ agarose gel electrophoresis. Amplicon library quality was evaluated with an Agilent 2100 Bioanalyzer (Agilent, USA) and Illumina (Kapa Biosciences, Woburn, MA, USA) library quantification kits, followed by paired-end sequencing on the NovaSeq PE250 platform. 


\section{Data optimization and analysis}

DNA amplicons were sequenced on the Illumina NovaSeq platform according to the manufacturer's recommendations. Oligonucleotide barcodes were used to assign sequences to samples, followed by removal of barcode and primer sequences. The FLASH program was used to merge the paired-end reads. The fqtrim program (v0.94) was then used to filter the sequence data to obtain high-quality clean sequence tags. Finally, the Vsearch software program was used to identify and remove chimeric sequences (v2.3.4). The complexity of species diversity was evaluated in samples through five alpha diversity indicators including the Chao1, observed species, reads, Good's coverage, and the Shannon diversity indices. Chao1 index was used to microbial richness. The higher Chao1 index indicate greater richness in the samples. Shannon index was used to measure microbial diversity. The greater Shannon index indicate higher diversity of the species in the sample. Sequence alignment was conducted with BLAST, and each representative sequence was taxonomically annotated using the SILVA database. Community composition within each sample was then summarized at the phylum and genus taxonomic classification levels for bacteria and at the order and genus levels for Archaea. The R language 'Vegan' package was used to construct a taxonomic classification heatmap and conduct RDA analysis.

\section{Sequence accession numbers}

Raw 16S rRNA gene sequences were deposited in the NCBI database under the BioSample accession Nos.SAMN21841898SAMN21841926 for Bacteria and SAMN21842788-SAMN21842816 for Archaea.

\section{Results And Discussion}

\section{Gas production among treatment groups}

Changes in daily gas production and cumulative gas production among the treatment groups are shown in Fig. 1. Across 40 days, daily biogas production in each treatment group exhibited two to three peaks around 7-20 days. All of the mixed fermentation groups exhibited the highest peaks on the 7th day and they were higher than those for pure sheep manure fermentation (Fig. 1a). The $S_{1} R_{2}$ and $S_{1} R_{1}$ groups exhibited the highest peaks, reaching 6.897 and $7.193 \mathrm{~m}^{3}$, respectively. Gas production ceased in the $\mathrm{R}$ group at 30 days, thereby completing the digestion process earlier than in the other treatments. The cumulative gas production in the six treatment groups (excluding the R group) clearly trended upwards over the first 20 days, followed by gradual increases in the treatments with higher rapeseed cake addition, and then a gradual slowing of the increasing trend (Fig. 1b).

Low temperatures considerably inhibit biogas production in fermentation systems, but rapeseed cake exhibits advantages of easy degradation and abundant nitrogen nutrient components that can balance $\mathrm{C} / \mathrm{N}$ ratios during fermentation and improve biogas production under adverse conditions (Stein et al. 2008; Yang et al. 2020; Han et al. 2020). In this study, biogas production from R and $S$ group treatments at low temperatures were $87.584 \mathrm{~m}^{3} \cdot \mathrm{t}^{-1}$ and $42.663 \mathrm{~m}^{3} \cdot \mathrm{t}^{-1}$, respectively. Comparison of the same conditions indicated that biogas production using rapeseed cake was 2.05 times that using sheep manure and it was also much higher than the $30 \mathrm{~mL} \cdot \mathrm{g}^{-1} \mathrm{VS}$ from low-temperature pig manure biogas production that was observed by Yao et al. (2020). Thus, the methane production potential from rapeseed cake was much greater at low temperature than from livestock and poultry manure, suggesting that the former is a good material for fermentation. Compared with fermentation using rapeseed cake and sheep manure alone, mixed fermentation greatly improved methane production. The $S_{1} R_{2}$ group exhibited the largest cumulative gas production, reaching $122.92 \mathrm{~m}^{3} \cdot \mathrm{t}^{-1}$, which was higher than the maximum methane production of $102.2 \mathrm{~mL} \cdot \mathrm{g}^{-1}$ observed by Kuang et al. (2020). Thus, mixed fermentation can balance the nutrient contents of fermentation raw materials and improve the low digestion efficiency of single-material fermentation, thereby increasing biogas production under adverse conditions (Zhao et al. 2018; Aworanti et al. 2017). 


\section{Dynamics of biogas production}

The key parameters for fitting cumulative fermentation gas production using different ratios of raw materials were modeled with a modified Gompertz equation (Table 3). The $R^{2}$ of all treatment groups was greater than 0.99 , indicating a good model fit. The $P, P_{m}$, and $R_{m}$ parameters of the $\mathrm{S}_{1} \mathrm{R}_{2}$ group were the largest. The $P_{1} P_{m}$, and $R_{m}$ parameters in the mixed fermentation increased with increasing rapeseed cake addition, while $\lambda$ decreased with increasing rapeseed cake addition. Thus, rapeseed cake was easy to degrade, and this process was synergistically associated with biogas production from sheep manure that improved the methane-producing rate and system stability.

Table 3

Parameters for the modified Gompertz model for biogas production among digester treatment groups

\begin{tabular}{|llllll|}
\hline Treatment group & $P\left(\mathrm{~m}^{3} \cdot \mathrm{t}^{-1}\right)$ & $P_{\mathrm{m}}\left(\mathrm{m}^{3} \cdot \mathrm{t}^{-1}\right)$ & $R_{\mathrm{m}}\left(\mathrm{m}^{3} \cdot(\mathrm{t} \cdot \mathrm{d})^{-1}\right)$ & $\lambda(\mathrm{d})$ & $R^{2}$ \\
\hline $\mathrm{S}$ & 42.663 & 43.081 & 1.981 & 2.362 & 0.999 \\
$\mathrm{R}$ & 87.584 & 89.233 & 5.134 & 0.729 & 0.997 \\
\hline $\mathrm{S}_{1} \mathrm{R}_{1}$ & 100.696 & 97.183 & 6.327 & 1.467 & 0.994 \\
$\mathrm{~S}_{2} \mathrm{R}_{1}$ & 88.068 & 87.398 & 4.854 & 1.474 & 0.998 \\
$\mathrm{~S}_{3} \mathrm{R}_{1}$ & 71.914 & 69.745 & 4.231 & 1.596 & 0.996 \\
$\mathrm{~S}_{4} \mathrm{R}_{1}$ & 67.614 & 66.187 & 4.057 & 2.108 & 0.998 \\
\hline $\mathrm{S}_{1} \mathrm{R}_{2}$ & 122.921 & 124.742 & 6.766 & 1.455 & 0.998 \\
\hline
\end{tabular}

\section{Changesin VFA contents, alkalinity, ammonia nitrogen, and pH during fermentation}

Volatile fatty acids (VFAs), alkalinity (AK), ammonia nitrogen (AN) and pH are important parameters for evaluating the effects of anaerobic fermentation and can reflect the stability of fermentation systems and the effective operation of anaerobic digestion. Generally, excessive accumulation of VFAs, too low alkalinity levels, too high ammonia nitrogen concentrations, and too low pH may all lead to collapsed fermentation systems (Lin et al. 2011). These parameters exhibited very different values in the $S$ and $R$ groups (Table 4 and Fig. 1), indicating that these properties were influenced by substrate materials. In general, the VFA concentrations of the four samples in the R group were higher, while the pH was lower, leading to a somewhat unstable system. When rapeseed cake and sheep manure were included in a mixed fermentation, the key parameter properties of fermentation broths were improved and near normal. 
Table 4

Physical and chemical properties of different digester treatment groups

\begin{tabular}{|c|c|c|c|c|}
\hline Treatment group & VFAs (mg/L) & $\mathrm{pH}$ & AN (mg/L) & $\mathrm{AK}(\mathrm{mg} / \mathrm{L})$ \\
\hline S_4 & 2,781 & 7.50 & 830 & 6,332 \\
\hline S_16 & 2,482 & 7.51 & 853 & 7,135 \\
\hline S_28 & 2,795 & 7.44 & 827 & 6,591 \\
\hline S_40 & 2,321 & 7.44 & 800 & 5,915 \\
\hline R_4 & 8,981 & 5.54 & 768 & 4,970 \\
\hline R_16 & 3,167 & 6.32 & 619 & 5,039 \\
\hline R_28 & 8,677 & 5.70 & 602 & 3,157 \\
\hline R_40 & 9,547 & 6.04 & 532 & 2,829 \\
\hline$S_{1} R_{1-4}$ & 4,327 & 5.92 & 796 & 5,470 \\
\hline$S_{1} R_{1-16}$ & 3,553 & 6.49 & 760 & 5,627 \\
\hline$S_{1} R_{1-28}$ & 3,547 & 6.47 & 723 & 4,995 \\
\hline$S_{1} R_{1-40}$ & 3,245 & 6.52 & 680 & 4,500 \\
\hline $\mathrm{S}_{2} \mathrm{R}_{1-4}$ & 4,005 & 6.44 & 812 & 5,509 \\
\hline$S_{2} R_{1-16}$ & 3,009 & 6.58 & 831 & 6,093 \\
\hline$S_{2} R_{1-28}$ & 3,470 & 6.48 & 769 & 5,112 \\
\hline$S_{2} R_{1-40}$ & 3,096 & 6.50 & 718 & 5,341 \\
\hline$S_{3} R_{1-4}$ & 3,698 & 6.56 & 811 & 5,594 \\
\hline$S_{3} R_{1-16}$ & 3,144 & 6.61 & 809 & 6,286 \\
\hline$S_{3} R_{1-28}$ & 3,101 & 6.62 & 721 & 5,715 \\
\hline$S_{3} R_{1-40}$ & 3,000 & 6.60 & 752 & 5,565 \\
\hline $\mathrm{S}_{4} \mathrm{R}_{1-4}$ & 3,561 & 6.77 & 823 & 5,570 \\
\hline $\mathrm{S}_{4} \mathrm{R}_{1-16}$ & 2,828 & 6.71 & 839 & 5,834 \\
\hline $\mathrm{S}_{4} \mathrm{R}_{1-28}$ & 3,148 & 6.79 & 810 & 5,742 \\
\hline $\mathrm{S}_{4} \mathrm{R}_{1-40}$ & 2,875 & 6.79 & 750 & 5,629 \\
\hline$S_{1} R_{2-} 4$ & 4,532 & 5.80 & 779 & 5,512 \\
\hline$S_{1} R_{2-16}$ & 3,422 & 6.49 & 740 & 5,665 \\
\hline $\mathrm{S}_{1} \mathrm{R}_{2-28}$ & 3,734 & 6.54 & 729 & 5,123 \\
\hline$S_{1} R_{2-40}$ & 3,683 & 6.47 & 677 & 4,140 \\
\hline
\end{tabular}




\section{Microbial diversity analysis}

A total of 2,257,936 and 2,915,212 high-quality bacterial and archaeal gene sequences, respectively, were obtained from the 29 samples after quality filtering, resulting in a total of 18,868 bacterial OTUs and 5,485 archaeal OTUs (Table 5). Diversity coverage for all samples was estimated at higher than 0.994 , suggesting adequate sampling of native sample diversity (Table 5). The Chao and Shannon index values for mixed fermentation communities (bacterial and archaeal) were both higher than those for single fermentation communities. Further, the 1:2 sheep manure and rapeseed cake mixture treatment group exhibited the highest bacterial and archaeal diversity. Thus, microbial community richness and diversity were highest in groups with higher gas production. 
Table 5

Bacterial and Archaeal community richness and diversity metrics for biogas digesters using different raw material ratios

\begin{tabular}{|c|c|c|c|c|c|c|c|c|c|c|}
\hline \multirow[t]{2}{*}{ Sample } & \multicolumn{5}{|l|}{ Bacteria } & \multicolumn{5}{|l|}{ Archaea } \\
\hline & Reads & OTUs & Chao1 & Shannon & Coverage & Reads & OTUs & Chao1 & Shannon & Coverage \\
\hline S_4 & 75,892 & 528 & 550.10 & 6.09 & 1 & 100,323 & 52 & 52.00 & 0.47 & 1 \\
\hline S_16 & 70,431 & 365 & 382.00 & 5.80 & 1 & 108,495 & 50 & 50.00 & 0.44 & 1 \\
\hline S_28 & 75,477 & 276 & 282.38 & 5.60 & 1 & 106,798 & 51 & 53.00 & 0.49 & 1 \\
\hline S_40 & 74,162 & 367 & 387.00 & 5.45 & 1 & 98,301 & 42 & 42.00 & 0.47 & 0.997 \\
\hline R_4 & 77,687 & 630 & 643.32 & 6.00 & 1 & 121,037 & 80 & 81.50 & 2.39 & 1 \\
\hline R_16 & 78,843 & 503 & 513.88 & 5.48 & 1 & 109,752 & 55 & 55.00 & 1.44 & 1 \\
\hline R_28 & 84,161 & 393 & 405.35 & 4.91 & 1 & 107,095 & 58 & 58.00 & 1.47 & 1 \\
\hline R_40 & 82,191 & 408 & 414.25 & 5.03 & 1 & 126,276 & 67 & 67.00 & 1.11 & 1 \\
\hline$S_{1} R_{1-4}$ & 80,948 & 762 & 791.81 & 6.79 & 1 & 86,500 & 275 & 276.91 & 3.92 & 1 \\
\hline$S_{1} R_{1-16}$ & 84,053 & 1031 & $1,034.58$ & 7.73 & 1 & 118,312 & 261 & 261.67 & 4.39 & 1 \\
\hline$S_{1} R_{1 \_} 28$ & 80,515 & 1056 & $1,088.44$ & 7.67 & 1 & 113,685 & 351 & 351.00 & 4.79 & 1 \\
\hline$S_{1} R_{1-40}$ & 75,257 & 988 & $1,015.51$ & 7.55 & 1 & 99,030 & 328 & 328.46 & 4.80 & 1 \\
\hline$S_{2} R_{1-4}$ & 80,499 & 558 & 575.07 & 5.66 & 1 & 90,458 & 222 & 222.60 & 3.76 & 1 \\
\hline$S_{2} R_{1-16}$ & 84,928 & 637 & 680.50 & 5.62 & 1 & 94,405 & 198 & 198.00 & 4.23 & 1 \\
\hline $\mathrm{S}_{2} \mathrm{R}_{1-28}$ & 78,095 & 559 & 589.64 & 5.75 & 1 & 96,694 & 226 & 226.60 & 4.20 & 1 \\
\hline$S_{2} R_{1-40}$ & 82,061 & 628 & 664.18 & 5.64 & 1 & 108,885 & 283 & 286.21 & 4.70 & 1 \\
\hline$S_{3} R_{1-4}$ & 70,415 & 529 & 545.59 & 5.69 & 1 & 102,956 & 222 & 122.00 & 2.54 & 1 \\
\hline$S_{3} R_{1-16}$ & 79,185 & 313 & 313.00 & 5.98 & 1 & 85,881 & 264 & 164.50 & 2.46 & 1 \\
\hline$S_{3} R_{1-28}$ & 79,954 & 589 & 600.47 & 6.01 & 1 & 71,215 & 249 & 257.00 & 3.28 & 1 \\
\hline $\mathrm{S}_{3} \mathrm{R}_{1-40}$ & 76,032 & 747 & 769.55 & 6.50 & 1 & 80,346 & 189 & 189.00 & 3.11 & 1 \\
\hline $\mathrm{S}_{4} \mathrm{R}_{1-4}$ & 67,787 & 561 & 582.21 & 6.12 & 1 & 76,973 & 106 & 106.41 & 1.47 & 0.995 \\
\hline $\mathrm{S}_{4} \mathrm{R}_{1-16}$ & 77,419 & 629 & 635.00 & 6.26 & 1 & 113,560 & 170 & 173.50 & 1.56 & 1 \\
\hline $\mathrm{S}_{4} \mathrm{R}_{1-28}$ & 77,615 & 554 & 555.31 & 6.07 & 1 & 91,488 & 167 & 167.50 & 1.97 & 1 \\
\hline $\mathrm{S}_{4} \mathrm{R}_{1-40}$ & 74,240 & 378 & 387.46 & 5.26 & 1 & 99,334 & 149 & 149.00 & 1.93 & 1 \\
\hline$S_{1} R_{2-4}$ & 83,654 & 793 & 809.92 & 7.17 & 1 & 110,863 & 360 & 361.15 & 5.18 & 1 \\
\hline$S_{1} R_{2-16}$ & 75,892 & 1,235 & $1,274.38$ & 8.08 & 1 & 108,000 & 466 & 479.36 & 5.70 & 1 \\
\hline$S_{1} R_{2-28}$ & 75,851 & 1,050 & $1,079.56$ & 7.81 & 1 & 100,617 & 273 & 273.00 & 3.97 & 1 \\
\hline $\mathrm{S}_{1} \mathrm{R}_{2-40}$ & 78,821 & 1,196 & $1,222.91$ & 8.11 & 1 & 93,274 & 190 & 190.00 & 3.09 & 1 \\
\hline
\end{tabular}




\begin{tabular}{|lllllllllll|}
\hline Sample & \multicolumn{3}{l}{ Bacteria } & \multicolumn{9}{c|}{ Archaea } \\
\cline { 2 - 12 } & Reads & OTUs & Chao1 & Shannon & Coverage & Reads & OTUs & Chao1 & Shannon & Coverage \\
\hline CK & 75,871 & 405 & 552.70 & 5.37 & 0.994 & 94,659 & 81 & 87.56 & 1.94 & 1 \\
\hline
\end{tabular}

\section{Bacterial community analysis}

A total of seven bacterial phyla and seven bacterial genera with relative abundances $>1 \%$ were identified in the biogas digesters (Fig. 2). Firmicutes, Proteobacteria, Bacteroidetes, and Actinobacteria were the dominant phyla among all samples, comprising total relative abundances of $>79.23 \%$ (Fig. 2a). The proportions of these taxa were relatively similar among biogas digesters and did not considerably differ with different raw material treatments. Thus, these groups are likely the most generally important taxa in digester fermentation systems and likely play important roles in hydrolyzing macromolecules, producing acid, and maintaining the stability of fermentation systems (Ng et al. 2016; Ariesyady et al. 2007; Regueiro et al. 2012; Li et al. 2015). The four aforementioned phyla accounted for the highest proportions (92.16\%) in the S group communities and the lowest proportions (79.23\%) in the CK communities. Synergistetes were also prominent members of communities, exhibiting relative abundances of $7.30 \%$, and their abundances varied with gas production. Synergistetes were most abundant in the $S_{1} R_{2}$ group (10.7\%) and least abundant in the $S$ group (4.09\%). Synergistetes and methanogens exhibit mutualistic metabolic relationships and typically are some of the core microbial groups in anaerobic digestion that contribute to methane production in digester systems (Baena et al. 2000). Temporal variation was also observed for bacterial taxa within each biogas digester treatment. For example, Synergistetes exhibited higher relative abundances on the 16th day in each group. Gas production in each group was relatively abundant before and after fermentation (Fig. 1), indicating that Synergistetes could play a critical role in gas production. Firmicutes exhibited higher relative abundances on the 4 th day in the biogas digesters of the $R, S_{1} R_{1}$, and $S_{1} R_{2}$ groups, while Actinobacteria exhibited increased relative abundances starting on the 16th day. Firmicutes degrade acidic substances that are produced in the early stage of fermentation, consistent with the above temporal variation in their abundances. The presence of Actinobacteria in the digesters could be due to the high sulfide content in rapeseed cake that would be degraded in the medium term (Ariesyady et al. 2007). Proteobacteria relative abundances rapidly increased with increased fermentation time in the biogas digesters of the $S, S_{3} R_{1}$, and $S_{4} R_{1}$ groups, peaking on the 28 th day $(44.27 \%, 30.75 \%$, and $29.77 \%$, respectively). Lastly, Bacteroidetes exhibited their highest relative abundances on the 4 th day of fermentation in the above groups (35.08\%, $23.24 \%$, and $36.09 \%$, respectively).

At the genus level, Lactobacillus (relative abundances of 14.68\%), Peptoniphilus (12.69\%), unclassified Synergistaceae(6.64\%), Bacteroides (5.74\%), and Pseudomonas (5.24\%) were dominant among all samples (Fig. 2b). Lactobacillus are members of the Firmicutes and have strong tolerance to acid, growing well under initial acidic conditions in digesters (Yang et al. 2019). Lactobacillus relative abundances decreased across fermentation time, with highest abundances in the R group (61.9\%), followed by the $S_{1} R_{2}$ (35.88\%) and $S_{1} R_{1}(21.2 \%)$ groups. Peptoniphilus are often found in feces (Ryu et al. 2021; Tiezzi et al. 2020) and degrade many substances including proteins, fats, and carbohydrates, but can also convert acetic acid and lactic acid into $\mathrm{H}_{2}$ and $\mathrm{CO}_{2}$ (Jang et al. 2014; Luo et al. 2014). Peptoniphilus were relatively abundant in the mixed fermentation treatment groups. Mixed fermentation may balance the nutrients in the fermentation systems, rendering it more suitable for the growth of these and other bacterial taxa (Kainthola et al. 2020; Zhao et al. 2018). Unclassified Synergistaceae are members of the Synergistetes and exhibited relative abundance distributions consistent with those of Synergistetes, wherein increased methane contents corresponded to their higher relative abundances. Bacteroides and Pseudomonas are members of Bacteroidetes and Proteobacteria, respectively, and play important roles in the efficient degradation of organic matter, often representing the dominant taxa in fermentation systems that use manure as raw materials (Ndubuisi-Nnaji et al. 2020). The relative abundances of Pseudomonas were higher in the S and CK groups (35.78\% and $12.41 \%$, respectively) relative to the other groups. When sheep manure and rapeseed cake were used in mixed fermentation, Pseudomonas abundances sharply dropped to almost zero. The relative abundances of Bacteroides were 
higher in the $S_{2} R_{1}, S, S_{3} R_{1}, S_{4} R_{1}$, and CK groups (10.19\%, 9.79\%, 9.35\%, 7.12\%, and $7.05 \%$, respectively), and their abundances all peaked on the 4 th day of fermentation, followed by sharp decreases.

\section{Archaeal community analysis}

A total of five archaeal orders and 10 genera (relative abundances $>1 \%$ ) were identified in biogas digesters with different raw material components (Fig. 3). At the order level, Methanomicrobiales was the most dominant group, with average relative abundances of $66.55 \%$ among the digesters. Methanosarcinales was the second most dominant group, with average relative abundances of $20.63 \%$ across digesters (Fig. 3a). Methanomicrobiales are often dominant in low-temperature biogas fermentation environments (McKeown et al. 2012) and exhibited increased abundances with increased rapeseed cake addition, such as observed in the $\mathrm{R}\left(71.18 \%-74.22 \%\right.$ relative abundances) and $\mathrm{S}_{1} \mathrm{R}_{2}(69.16 \%-72.13 \%)$ groups. The proportions of Methanobacteriales in each group fluctuated to some extent, but overall trends were not obvious, and thus, substrate ratios did not obviously affect their abundances.

Among the nine archaeal genera identified in the 29 samples, Methanogenium was the most dominant (average relative abundances of $41.82 \%$ ), followed by Methanoculleus and Methanobrevibacter (16.55 and 14.33\%, respectively), and then Nitrososphaera and Methanocorpusculum (7.99\% and 7.57\%, respectively). The above methanogens exhibit hydrogenotrophic methanogenesis pathways (Fig. 3b). Methanogenium, Methanoculleus, and Methanocorpusculum are all members of the Methanomicrobiales, with Methanogenium and Methanocorpusculum being common in low-temperature environments. The former has a wide distribution range, with the lowest growth temperatures being observed at $0^{\circ} \mathrm{C}$. In the low temperature environments of Qinghai, Methanogenium are often dominant (Han et al. 2021; Asakawa et al. 2003; Chong et al. 2002), consistent with the rural household biogas digesters in this study $\left(15.2-17.8^{\circ} \mathrm{C}\right)$, where they were also dominant. Likewise, Methanocorpusculum often appear in low-temperature anaerobic digestion systems that use feces as raw materials (Han et al. 2021; Gao et al. 2014). Among the above methanogens, Methanogenium exhibited the highest relative abundances (56.57\%) in the S group that used sheep manure as raw material, while the abundances of Methanocorpusculum were relatively equivalent among groups. Methanoculleusare often present in fermentation systems with high organic loads and exhibit high tolerance to environmental conditions with high VFA concentrations (Bae et al. 2020; Mathai et al. 2020). Methanoculleus exhibited abundances as high as $35.86 \%$ in the $\mathrm{R}$ group that had average VFA concentrations of $7,593 \mathrm{mg} / \mathrm{L}$. In addition, Methanoculleus exhibited their highest relative abundances on the 4th day of fermentation, regardless of materials used in the treatment, and their abundances were consistent with variation in VFAs (Table 4). Methanobrevibacter are members of the Methanobacteriales. Although this genus often appears in lowtemperature environments, its existence may be more dependent on the characteristics of fermentation materials, especially in anaerobic fermentation systems using livestock manure as raw materials, where it exhibits high relative abundances (Rodriguez-Sanchez et al. 2020; Shanmugam et al. 2014). The relative abundances of Methanobrevibacter were highest in this study in the mixed fermentation groups that had relatively high contents of sheep manure, including the $S_{4} R_{1}$ and $S_{3} R_{1}$ groups (17.13\% and $17.12 \%$, respectively), followed by the $S_{1} R_{1}$ and $S_{1} R_{2}$ groups (14.83\% and $13.69 \%$, respectively). Thus, it is likely that Methanobrevibacter is more adapted to the mixed anaerobic environments that were dominated by feces and may play important roles in methane production (Shanmugam et al. 2014). Although Nitrososphaera did not participate in the methanogenic pathway, it often appears in high nitrogen environments such as feces (Enebe et al. 2021; Pizzeghello et al. 2021). The relative abundances of Nitrososphaera were positively correlated with high contents of sheep manure in this study, which was reflected in the group with more sheep manure, the higher its relative abundances.

\section{OTU distributions}

To understand the overall differences in communities across biogas digesters, the distributions of the 30 most abundant OTUs were evaluated (Fig. 4). Among the 30 bacterial genera and OTUs with the highest abundances, shared genera primarily originated from seven phyla. Firmicutes $(46.74 \%)$ exhibited the highest relative abundances, followed by the 
Proteobacteria (15.76\%), Bacteroidetes (13.24\%), Actinobacteria (11.3\%), and Synergistetes (7.3\%) (Fig. 4a). The abundances of genera among biogas digesters with different starting material ratios were quite different. For example, Lactobacillus abundances were as high as $56.65 \%, 27.13 \%$, and $19.95 \%$ in the $R, S_{1} R_{2}$, and $S_{1} R_{1}$ group biogas digesters, respectively, but their abundances were extremely low in the biogas digesters with higher sheep manure contents.

Shared archaeal genera among the digesters mainly derived from 14 orders, with the highest relative abundances corresponding to the Methanomicrobiales (66.55\%) (Fig. 4b). A total of 14 genera could not be classified at the genus level, including those that could only be classified as Euryarchaeota, Archaea, and Nitrososphaeria. As observed for the bacterial communities, archaeal genera abundances widely varied among different biogas digesters.

\section{Correlations between digester microbial community compositions and environmental factors}

RDA was conducted to evaluate the relationships between microbial community compositions and environmental factors among samples (Fig. 5). Bacterial community structures were mainly related to VFA concentrations and pH (Fig. 5a). Indeed, VFA concentration was the most important factor associated with bacterial community variation among biogas digesters with different raw material ratios. In addition, VFA concentrations were positively correlated with Lactobacillus abundances. Lactobacillus were abundant in the biogas digesters with high VFA concentrations. VFA concentrations were relatively highest on the 4th day of digester fermentations due to the accumulation of acid in the pre-fermentation period, consistent with Lactobacillus abundances that were highest on the 4th day, followed by subsequent gradual decreases (Table 4). Thus, VFAs likely controlled the abundances of Lactobacillus, consistent with previous studies (Shi et al. 2021). pH also concomitantly exhibited apparent effects on the distributions of bacterial groups and was positively correlated with the abundances of Bacteroides and Pseudomonas. These two bacterial taxa exhibited highest abundances in biogas digesters with $\mathrm{pH}>6.5$ (Table 4). Thus, $\mathrm{pH}$ significantly affected Bacteroides and Pseudomonas abundances, consistent with the results of Choure and Al-Mur (Choure et al. 2021; Al-Mur et al. 2021). Among the environmental factors, AK and AN exhibited non-significant correlations with bacterial community structures.

Similar to the bacterial community structures, archaeal community structures were also primarily related to VFA concentrations and pH (Fig. 5b). In addition, VFAs were also the most important factor contributing to differences in archaeal communities among biogas digesters and were positively correlated with Methanoculleus and Methanothrix abundances. In anaerobic fermentation systems with highly variable VFA concentrations, the relative abundances of Methanoculleus and Methanothrix also differ (Lim et al. 2020). Further, both Methanobrevibacter and Methanobacterium abundances were positively correlated with pH, consistent with previous studies (Zhao et al. 2020; Fones et al. 2021). As observed for the bacterial communities, other environmental factors, including AK and AN, also did not exhibit significant effects on archaeal communities.

\section{Conclusions}

Anaerobic fermentation is a clean and efficient way to utilize agricultural waste resources like rapeseed cake and sheep manure. The evaluation of low-temperature mixed anaerobic fermentation within seven biogas digesters using different raw material ratios indicated that a dry matter ratio of sheep manure and rapeseed cake of 1:2 corresponded to the highest cumulative biogas production $\left(122.92 \mathrm{~m}^{3} \cdot \mathrm{t}^{-1}\right)$. High-throughput sequencing was used to investigate the microbial communities associated with the fermentation process using different digester material ratios. Lactobacillus, Peptoniphilus, unclassified Synergistaceae, Bacteroides, and Pseudomonas were the most dominant bacterial taxa among the 29 digester samples analyzed here, and their abundances varied with the ratios of raw materials. Concomitantly, Methanogenium and Methanoculleus were the main gas-producing archaea identified in the digesters. Specifically, Methanogenium exhibited higher abundances in biogas digesters with higher sheep manure contents, while Methanoculleus exhibited higher abundances in biogas digesters with higher rapeseed cake contents. VFA concentrations and pH were the primary factors

Page $13 / 20$ 
associated with differences in archaeal and bacterial community structures among all digesters of this study. This study provides a theoretical basis for the utilization of agricultural waste resources like rapeseed cake and sheep manure, while also providing a framework for the promotion and application of low-temperature anaerobic fermentation treatment of agricultural waste in Qinghai Province.

\section{Declarations}

\section{Declarations}

There is no conflict of interest.

\section{Acknowledgment:}

This work was supported by the National Natural Science Foundation of Qinghai Province (2021-ZJ-921), and the Key Laboratory Project of Qinghai Science \& Technology Department (2020-ZJ-Y02).

\section{References}

1. Al-Mur BA, Pugazhendi A, Jamal MT (2021) Application of integrated extremophilic (halo-alkalo-thermophilic) bacterial consortium in the degradation of petroleum hydrocarbons and treatment of petroleum refinery wastewater under extreme condition. J Hazard Mater 413:125351. https://doi.org/10.1016/j.jhazmat.2021.125351

2. Arelli V, Mamindlapelli NK, Begum S et al (2021) Solid state anaerobic digestion of food waste and sewage sludge: Impact of mixing ratios and temperature on microbial diversity, reactor stability and methane yield. Sci Total Environ 793:148586. https://doi.org/10.1016/J.SCITOTENV.2021.148586

3. Ariesyady HD, Ito T, Okabe S (2007) Functional bacterial and archaeal community structures of major trophic groups in a full-scale anaerobic sludge digester. Water Res 41:1554-1568. https://doi.org/10.1016/j.watres.2006.12.036

4. Asakawa S, Nagaoka K (2003) Methanoculleus Bourgensis, Methanoculleus Olentangyi and Methanoculleus Oldenburgensis are Subjective Synonyms. Int J Syst Evol MicroBiol 53:1551-1552. https://doi.org/10.1099/ijs.0.025080

5. Aworanti OA, Agarry SE, Ogunleye $O 0$ (2017) Biomethanization of the Mixture of Cattle Manure, Pig Manure and Poultry Manure in Co-Digestion with Waste Peels of Pineapple Fruit and Content of Chicken-Gizzard-Part II: Optimization of Process Variables. The Open Biotechnology Journal 11:54-71. https://doi.org/10.2174/1874070701711010054

6. Bae JS, Yoon YM, Shin SK et al (2020) Biogas potential and methanogenic community shift in in-situ anaerobic sewage sludge digestion with food waste leachate additions. Applied Biological Chemistry 63:1-20.

https://doi.org/10.1186/s13765-020-00546-6

7. Baena S, Fardeau ML, Labat M et al (2000) Aminobacterium mobile sp. nov., a new anaerobic amino-acid-degrading bacterium. Int J Syst Evol MicroBiol 50:259-264. https://doi.org/10.1099/00207713-50-1-259

8. Chong SC, Liu YT, Cummins M et al (2002) Methanogenium marinum sp. nov., a H2-using methanogen from Skan Bay, Alaska, and kinetics of H2 utilization. Antonie Van Leeuwenhoek 81:263-270.

https://doi.org/10.1023/a:1020535222281

9. Choure K, Parsai S, Kotoky R et al (2021) Comparative Metagenomic Analysis of Two Alkaline Hot Springs of Madhya Pradesh, India and Deciphering the Extremophiles for Industrial Enzymes. Front Genet. https://doi.org/10.3389/FGENE.2021.643423

10. Elmitwalli TA, van Lier J, Zeeman G et al (2004) Treatment of domestic sewage at low temperature in a two-anaerobic step system followed by a trickling filter. Water Sci Technol 48:199-206. https://doi.org/10.2166/wst.2004.0840 
11. Enebe MC, Babalola $O O$ (2021) The Influence of Soil Fertilization on the Distribution and Diversity of Phosphorus Cycling Genes and Microbes Community of Maize Rhizosphere Using Shotgun Metagenomics. Genes 12:1022. https://doi.org/10.3390/genes12071022

12. Fones EM, Colman DR, Kraus EA et al (2021) Diversification of methanogens into hyperalkaline serpentinizing environments through adaptations to minimize oxidant limitation. ISME J 15:1121-1135.

https://doi.org/10.1038/s41396-020-00838-1

13. Gao PK, Li GQ, Zhao LX et al (2014) Dynamic processes of indigenous microorganisms from a low-temperature petroleum reservoir during nutrient stimulation. J Biosci Bioeng 117:215-221.

https://doi.org/10.1016/j.jbiosc.2013.07.009

14. Han R, Liu L, Meng Y et al (2021) Archaeal and bacterial community structures of rural household biogas digesters with different raw materials in Qinghai Plateau. Biotechnol Lett 43:1337-1348. https://doi.org/10.1007/s10529-021-03105-1

15. Han R, Zhu DR, Xing JW et al (2020) The efect of temperature fuctuation on the microbial diversity and community structure of rural household biogas digesters at Qinghai Plateau. Arch Microbiol 202:525-538.

https://doi.org/10.1007/s00203-019-01767-0

16. Hu DX, Xu J, Chen ZB et al (2017) Performance of a pilot split-type anaerobic membrane bioreactor (AnMBR) treating antibiotics solvent wastewater at low temperatures. Chem Eng J 325:502-512.

https://doi.org/10.1016/j.cej.2017.05.086

17. Jang HM, Kim JH, Ha JH (2014) Bacterial and methanogenic archaeal communities during the single-stage anaerobic digestion of high-strength food wastewater. Bioresour Technol 165:174-182.

https://doi.org/10.1016/j.biortech.2014.02.028

18. Kainthola J, Kalamdhad AS, Goud VV (2020) Optimization of process parameters for accelerated methane yield from anaerobic co-digestion of rice straw and food waste. Renewable Energy 149:1352-1359.

https://doi.org/10.1016/j.renene.2019.10.124

19. Kuang Y, Gao Y, Zhang J et al (2020) Effect of initial pH on the sludge fermentation performance enhanced by aged refuse at low temperature of $10^{\circ} \mathrm{C}$. Environ Sci Pollut Res 27:31468-31476. https://doi.org/10.1007/s11356-020-09306$\mathrm{x}$

20. Li JB, Rui JP, Yao MJ (2015) Substrate Type and Free Ammonia Determine Bacterial Community Structure in Full-Scale Mesophilic Anaerobic Digesters Treating Cattle or Swine Manure. Front Microbiol 6:1337. https://doi.org/10.3389/fmicb.2015.01337

21. Li PP, He C, Li G et al (2020) Biological pretreatment of corn straw for enhancing degradation efficiency and biogas production. Bioengineered 11:251-260. https://doi.org/10.1080/21655979.2020.1733733

22. Lim JX, Zhou Y, Vadivelu VM (2020) Enhanced volatile fatty acid production and microbial population analysis in anaerobic treatment of high strength wastewater. Journal of Water Process Engineering 33:101058-101058. https://doi.org/10.1016/j.jwpe.2019.101058

23. Lin J, Zuo J, Gan L et al (2011) Effects of mixture ratio on anaerobic co-digestion with fruit and vegetable waste and food waste of China. Journal of Environmental Sciences Journal of Environmental Sciences 23:1403-1408. https://doi.org/10.1016/S1001-0742(10)60572-4

24. Luo G, Angelidaki I (2014) Analysis of bacterial communities and bacterial pathogens in a biogas plant by the combination of ethidium monoazide, PCR and lon Torrent sequencing. Water Res 60:156-163.

https://doi.org/10.1016/j.watres.2014.04.047

25. Mathai PP, Nicholes MS, Venkiteshwaran K et al (2020) Dynamic shifts within volatile fatty acid-degrading microbial communities indicate process imbalance in anaerobic digesters. Appl Microbiol Biotechnol 104:4563-4575. https://doi.org/10.1007/s00253-020-10552-9

26. McKeown RM, Hughes D, Collins G et al (2012) Low-temperature anaerobic digestion for wastewater treatment. Curr Opin Biotechnol 23:444-451. https://doi.org/10.1016/j.copbio.2011.11.025

Page $15 / 20$ 
27. Ndubuisi-Nnaji UU, Ofon UA, Asamudo NU et al (2020) Enhanced Biogas and Biofertilizer Production from Anaerobic Codigestion of Harvest Residues and Goat Manure. Journal of Scientific Research and Reports 26:1-13. https://doi.org/10.9734/jsrr/2020/v26i330231

28. Ng KK, Shi XQ, Ong SL et al (2016) Pyrosequencing reveals microbial community profile in anaerobic bio-entrapped membrane reactor for pharmaceutical wastewater treatment. Bioresour Technol 200:1076-7079.

https://doi.org/10.1016/j.biortech.2015.10.100

29. Pizzeghello D, Bellin L, Nardi S et al (2021) Wood-Based Compost Affects Soil Fertility and the Content of Available Forms of Nutrients in Vineyard and Field-Scale Agroecosystems. Agronomy 11:518-518.

https://doi.org/10.3390/AGRONOMY11030518

30. Regueiro L, Veiga P, Figueroa M et al (2012) Relationship between microbial activity and microbial community structure in six full-scale anaerobic digesters. Microbiol Res 167:581-589. https://doi.org/10.1016/j.micres.2012.06.002

31. Rodriguez-Sanchez A, Muñoz PB, Hurtado MM et al (2020) Analysis of microbial communities involved in organic matter and nitrogen removal in a full-scale moving bed biofilm reactor located near the Polar Arctic Circle. Int Biodeterior Biodegrad 146:104830. https://doi.org/10.1016/j.ibiod.2019.104830

32. Ryu SW, Kim JS, Oh BS et al (2021) Peptoniphilus faecalis sp. nov., isolated from swine faeces. Int J Syst Evol MicroBiol 71:004836. https://doi.org/10.1099/IJSEM.0.004836

33. Shanmugam SR, Chaganti SR, Lalman JA et al (2014) Using a statistical approach to model hydrogen production from a steam exploded corn stalk hydrolysate fed to mixed anaerobic cultures in an ASBR. Int J Hydrog Energy 39:1000310015. https://doi.org/10.1016/j.ijhydene.2014.04.115

34. Shi ZG, Zhang L, Yuan HR et al (2021) Oyster shells improve anaerobic dark fermentation performances of food waste: Hydrogen production, acidification performances, and microbial community characteristics. Bioresour Technol 335:125268-125268. https://doi.org/10.1016/J.BIORTECH.2021.125268

35. Stein HH, Lagos LV, Casas GA (2016) Nutritional value of feed ingredients of plant origin fed to pigs. Anim Feed Sci Technol 218:33-69. https://doi.org/10.1016/j.anifeedsci.2016.05.003

36. Tao Z, Chen C, Yang Q et al (2021) Understanding the impact of allicin for organic matter release and microorganism community in anaerobic co-digestion of food waste and waste activated sludge. Sci Total Environ 776:145598. https://doi.org/10.1016/J.SCITOTENV.2021.145598

37. Tian YL, Li SS, Li Y et al (2019) Cadmium Addition Effects on Anaerobic Digestion with Elevated Temperatures. Energies 12:2367. https://doi.org/10.3390/en12122367

38. Tiezzi F, Bergamaschi M, Howard J et al (2020) Feed efficiency and behavior are associated with gut microbiome in three breeds of pigs. J Anim Sci 98:24-24. https://doi.org/10.1093/jas/skaa278.044

39. Tiwari BR, Rouissi T, Brar SK et al (2021) Critical insights into psychrophilic anaerobic digestion: Novel strategies for improving biogas production. Waste Manag 131:513-526. https://doi.org/10.1016/J.WASMAN.2021.07.002

40. Wang AD, Zou DS, Zhang LQ et al (2019) Environmental risk assessment in livestock manure derived biochars. RSC Adv 9:40536-40545. https://doi.org/10.1039/c9ra08186k

41. Wang SN, Yuan RF, Liu CC et al (2020) Effect of Fe2+ adding period on the biogas production and microbial community distribution during the dry anaerobic digestion process. Process Saf Environ Prot 136:234-241. https://doi.org/10.1016/j.psep.2019.12.031

42. Yang B, Yin F, Wang CM et al (2019) Construction of biogas metabolic pathway in a low-temperature biogas fermentation syste. Energy Science \& Engineering 7:3160-3173. https://doi.org/10.1002/ese3.488

43. Yang HY, Zhou B, Li CB et al (2019) An optimal self-excited heating method for biogas production under cold climate. The Journal of Engineering 2019:5094-5098. https://doi.org/10.1049/joe.2018.9236

44. Yao Y, Huang GD, An CJ et al (2020) Anaerobic digestion of livestock manure in cold regions: Technological advancements and global impacts. Renew Sustain Energy Rev 119:109494-109494. 
https://doi.org/10.1016/j.rser.2019.109494

45. Zhai SM, Li M, Xiong YH et al (2020) Dual resource utilization for tannery sludge: Effects of sludge biochars (BCs) on volatile fatty acids (VFAs) production from sludge anaerobic digestion. Bioresour Technol 316:123903.

https://doi.org/10.1016/j.biortech.2020.123903

46. Zhang HB, Zhang PY, Ye J et al (2016) Improvement of methane production from rice straw with rumen fluid pretreatment: A feasibility study. Int Biodeterior Biodegrad 113:9-16. https://doi.org/10.1016/j.ibiod.2016.03.022

47. Zhao J, Li Y, Marandola C et al (2020) Comparison of the microbial communities in anaerobic digesters treating high alkalinity synthetic wastewater at atmospheric and high-pressure (11 bar). Bioresour Technol 318:124101-124101. https://doi.org/10.1016/j.biortech.2020.124101

48. Zhao YB, Sun FR, Yu JD et al (2018) Co-digestion of oat straw and cow manure during anaerobic digestion: Stimulative and inhibitory effects on fermentation. Bioresour Technol 269:143-152. https://doi.org/10.1016/j.biortech.2018.08.040

\section{Figures}
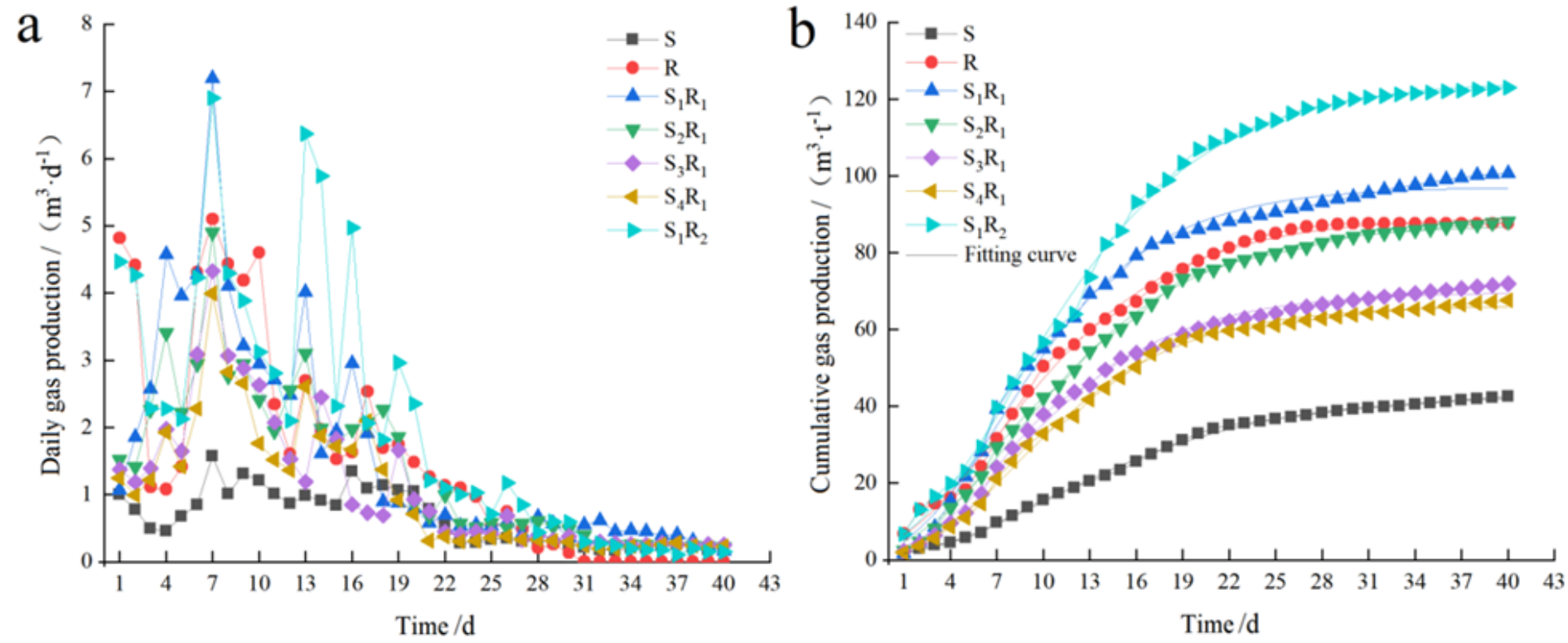

Figure 1

Variation in gas production among different digester treatment groups 


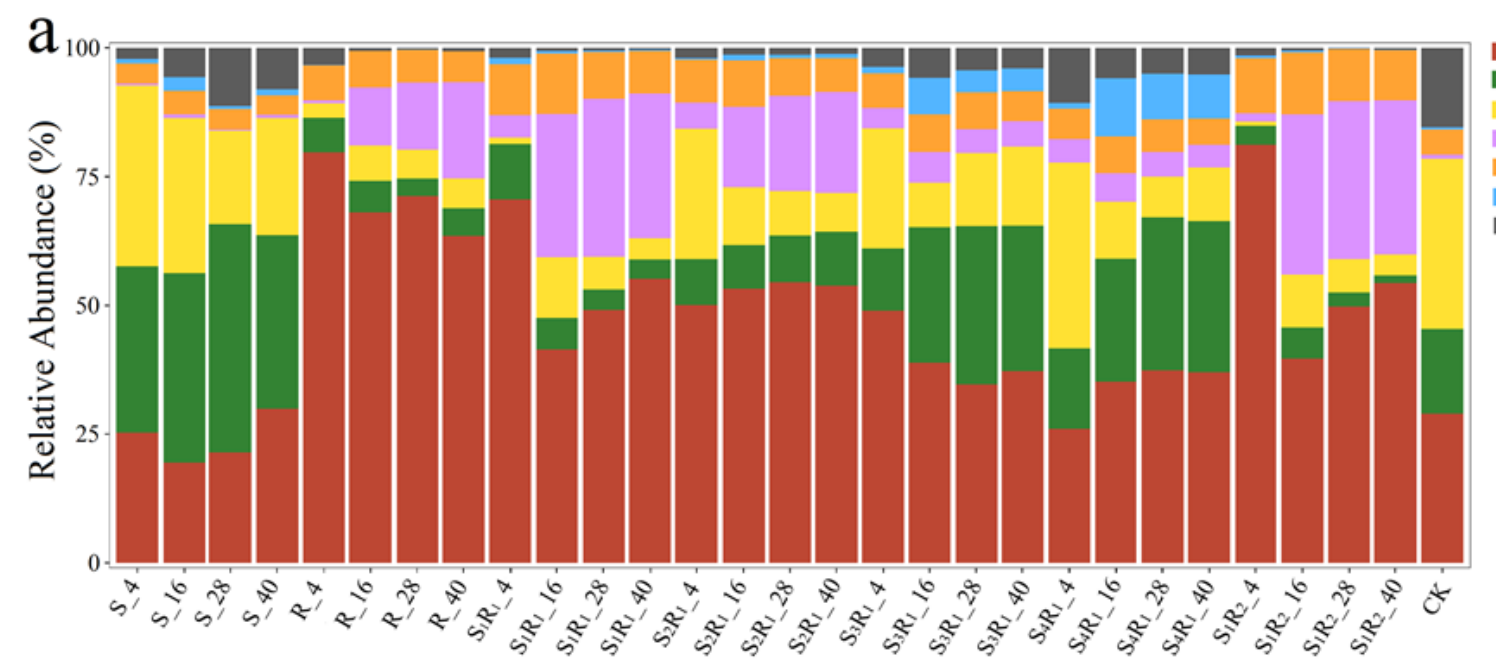

Firmicutes

Proteobacteria

Bacteroidetes

Actinobacteria

Synergistetes

Planctomycetes

Others

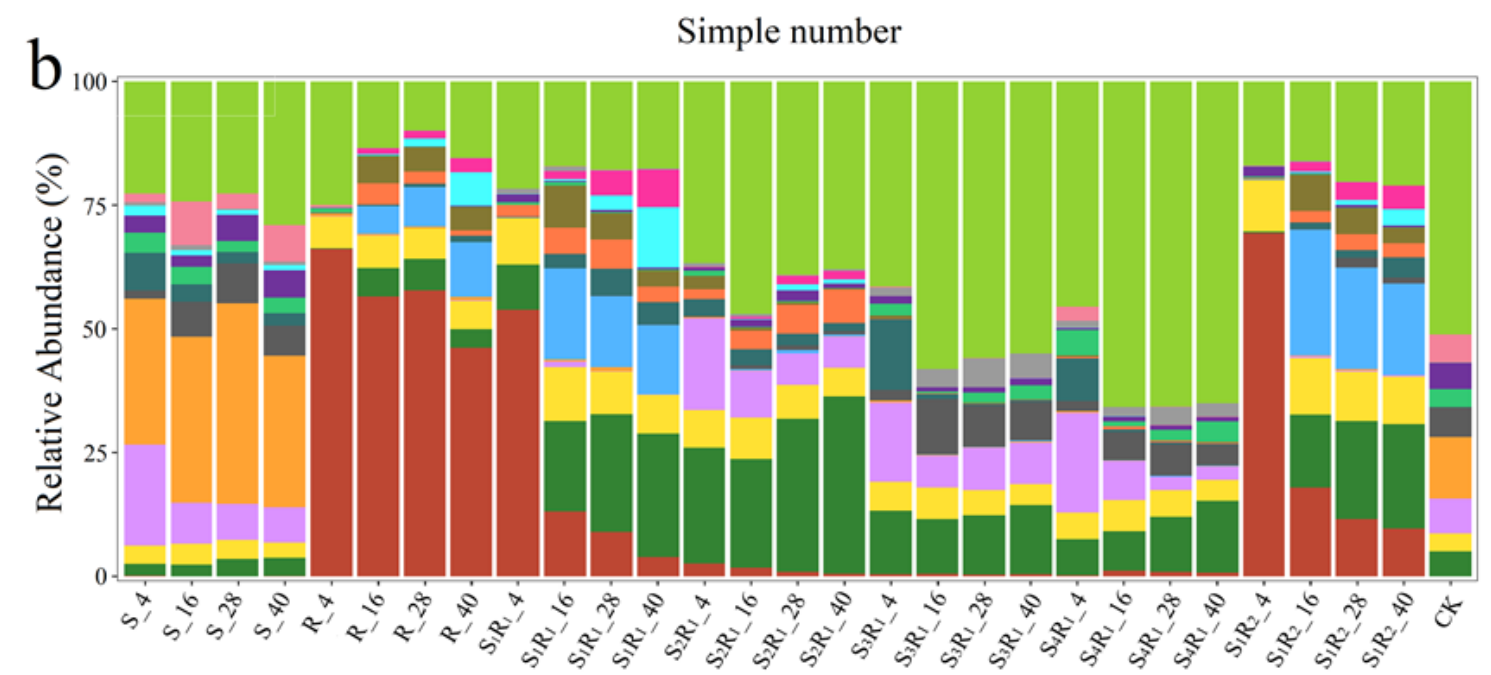

Lactobacillus

Peptoniphilus

Synergistaceae_unclassified Bacteroides

Pseudomonas

Coriobacteriales_unclassified

- Pseudoramibacter

Lachnospiraceae_unclassified

Neoscardovia

- Prevotella

Proteiniphilum

[Christensenellaceae_R-7_group

Caproiciproducens

- Olsenella

Pusillimonas

DMER64

Others

Simple number

\section{Figure 2}

Bacterial community structures in digesters at the a) phylum and b) genus levels 


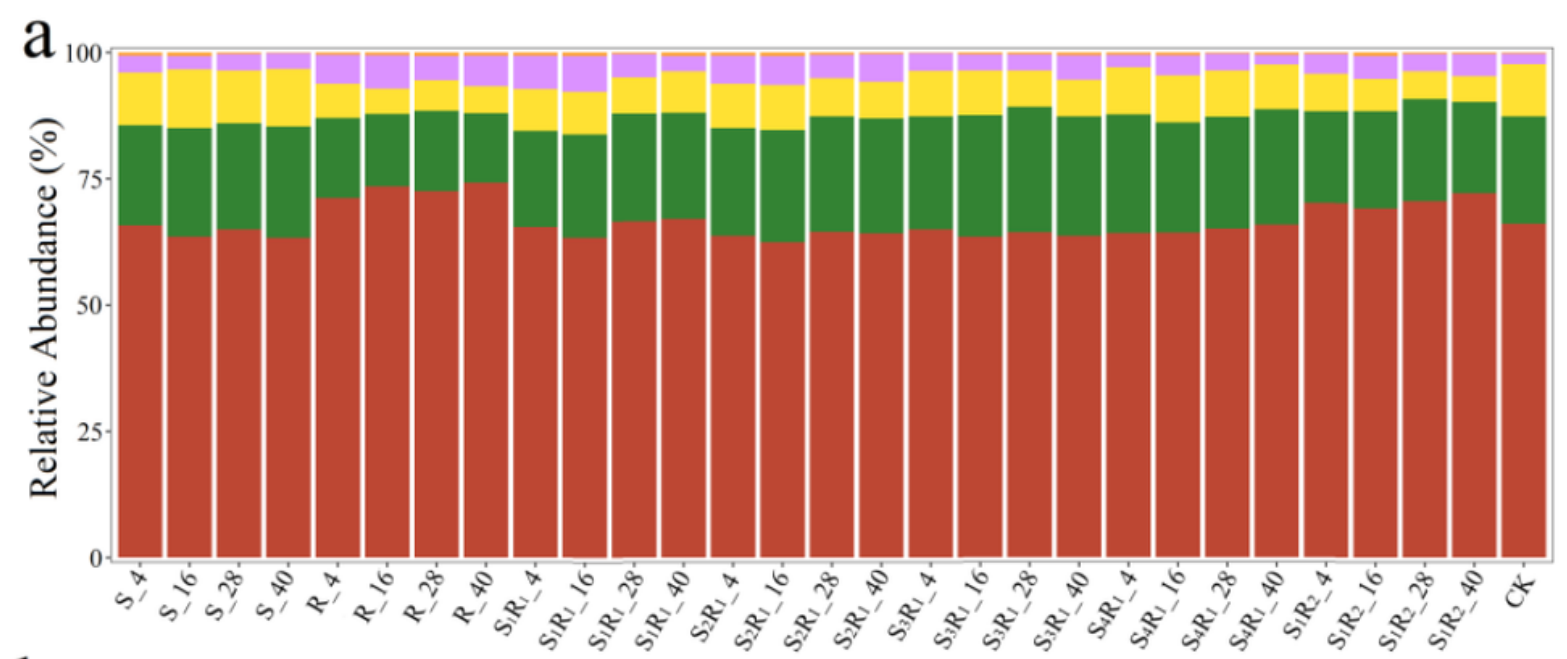

Methanomicrobiales

Methanobacteriales

Nitrososphaerales

Methanosarcinales

Others

b

Simple number

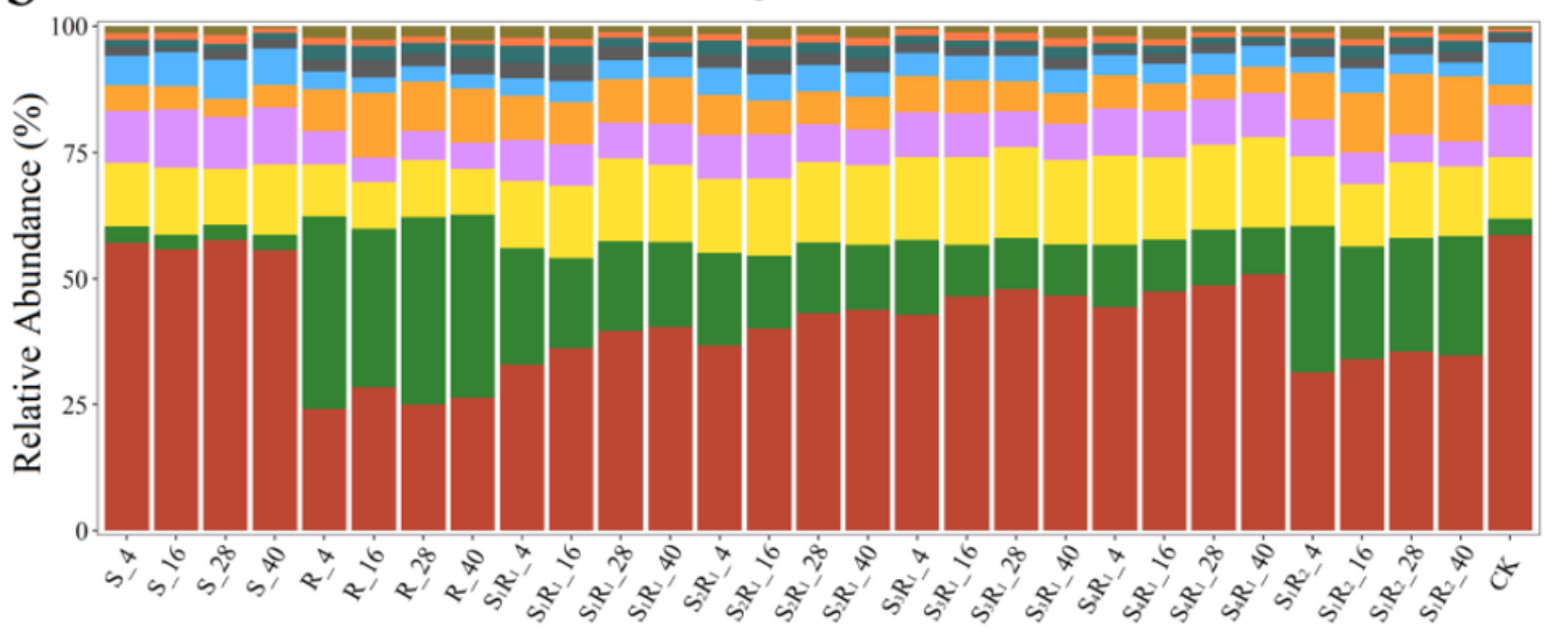

Simple number

\section{Figure 3}

Archaeal community structures in digesters at the a) order and b) genus levels 
a

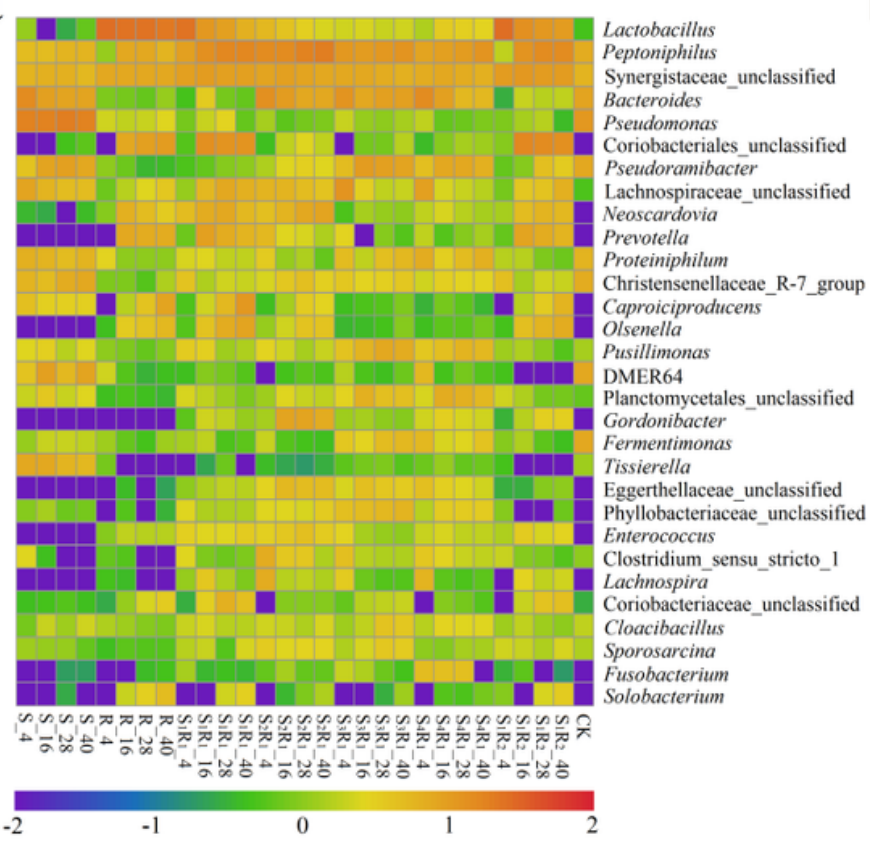

Relative abundance of community $(\%)$ $\mathrm{b}$

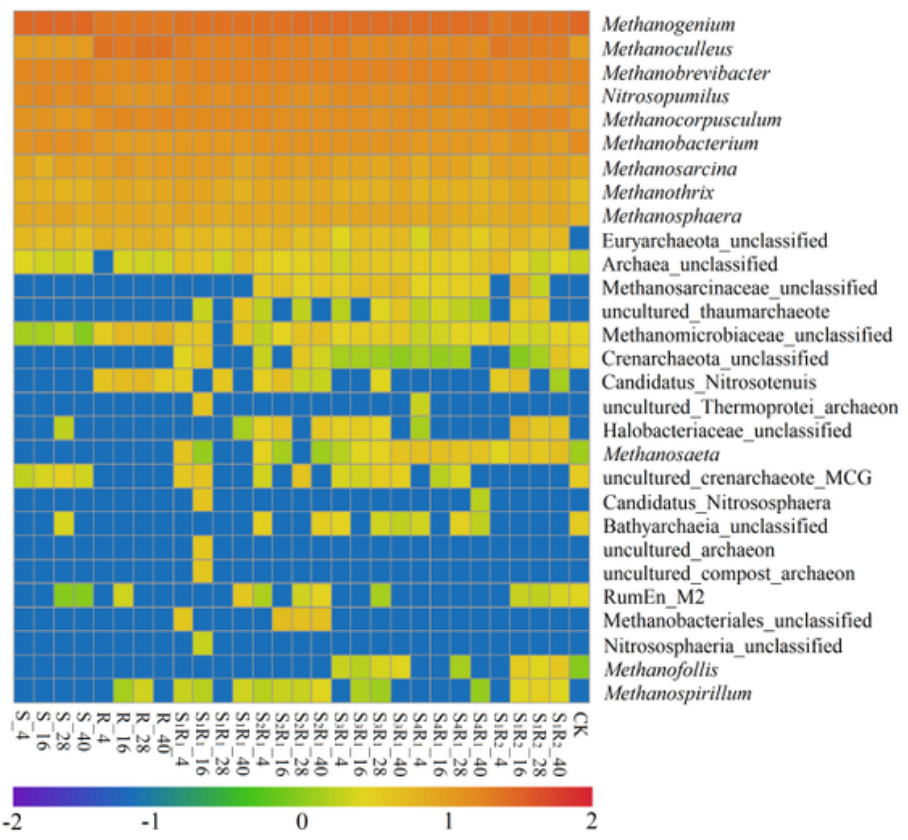

Relative abundance of community $(\%)$

\section{Figure 4}

Heatmap showing the 30 most abundant a) bacterial andb) archaeal OTUs among biogas digesters
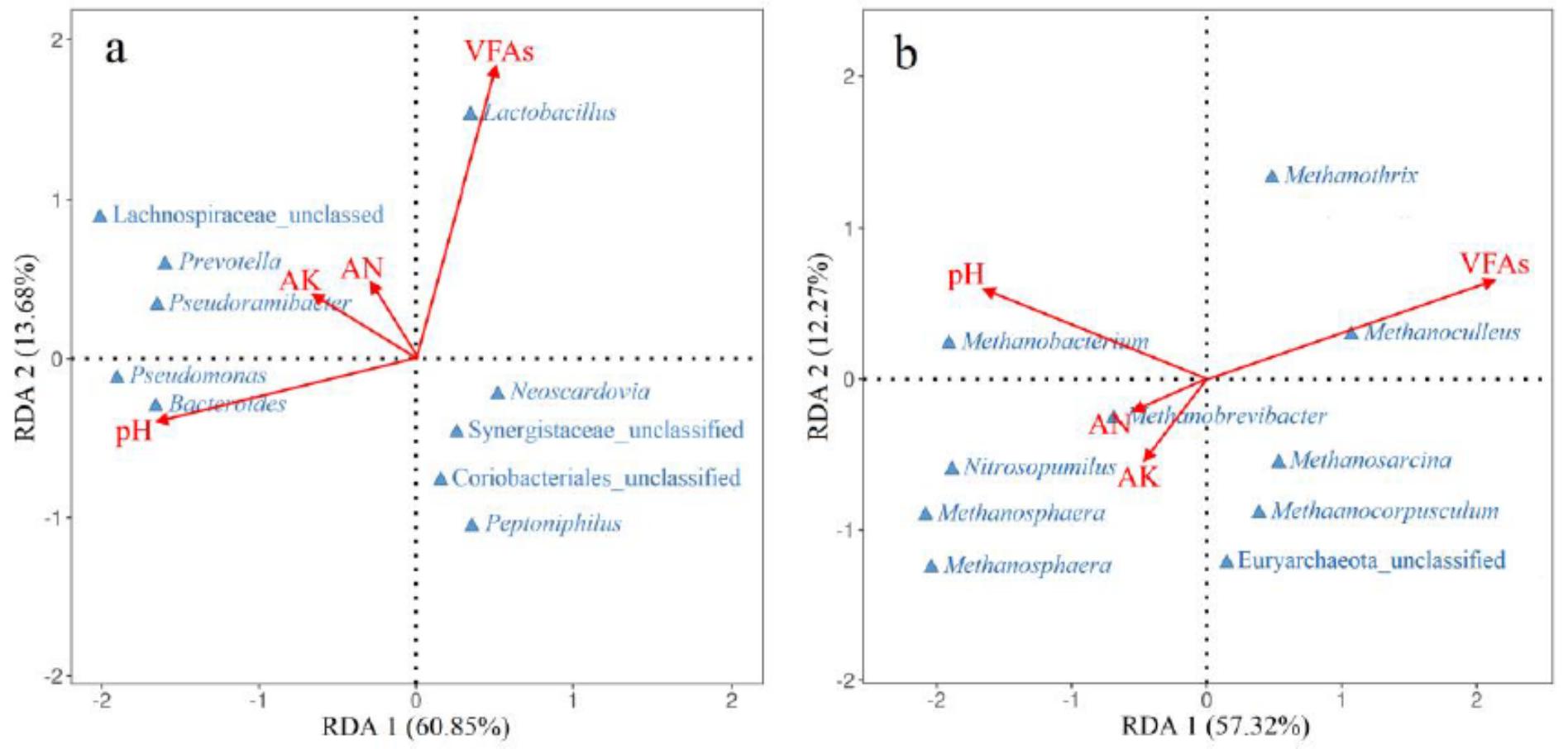

\section{Figure 5}

RDA analysis of the a) bacterial and b) archaeal community composition and relevant environmental factors within biogas digesters. 